\title{
No sex-related difference in achievement of treatment-free remission following treatment with tyrosine kinase inhibitors in chronic myeloid leukemia
}

\author{
Hiroki Yamaguchi ${ }^{1} \cdot$ Koiti Inokuchi $^{1}$ - of the Kanto CML Study Group
}

Received: 5 March 2020 / Revised: 17 March 2020 / Accepted: 17 March 2020 / Published online: 31 March 2020

(c) Japanese Society of Hematology 2020

In a comparison of studies in which tyrosine kinase inhibitor (TKI) was discontinued, Ureshino et al. pointed out that one of the reasons for the lower treatment-free remission (TFR) rate $(38.5 \%)$ reported in our study, "Treatment-free remission after first-line dasatinib treatment in patients with chronic myeloid leukemia in the chronic phase" [1] was that most of the registered cases were female (nine male, 17 female). Mahon et al. have shown a significantly lower TFR rate in female compared to male in the STIM study [2]. Similarly, the JALSG-STIM213 study by Takahashi et al. in which more males were registered (42 male, 26 female), showed a favorable TFR rate $(67.6 \%)$ even compared to other discontinued studies [3]. However, the results of a long-term follow-up of the STIM study showed no patient sex-related differences in the achievement of TRF [4]. In addition, there have been no reports showing sex-related differences in the achievement of TRF in past studies where TKI was discontinued [5]. Although our study also showed no significant difference between male (3/9 [33.3\%]) and female, (7/17 [41.2\%]), the TFR rate was rather higher in female [1]. Collectively, these studies demonstrate that there are no sex-related differences in the achievement of TFR due to TKI. The ongoing J-SKY study in Japan, a nationwide survey of studies in which TKI was discontinued, includes a large number of cases and thus, will clarify whether there is a sex-related difference in the achievement of TFR due to TKI.

\section{References}

1. Yamaguchi H, Takezako N, Ohashi K, Oba K, Kumagai T, Kozai $\mathrm{Y}$, et al. Treatment-free remission after first-line dasatinib treatment in patients with chronic myeloid leukemia in the chronic phase: the D-NewS study of the Kanto CML study Group. Int J Hematol. 2020;111(3):401-8.

2. Mahon FX, Réa D, Guilhot J, Guilhot F, Huguet F, Nicolini F, et al. Discontinuation of imatinib in patients with chronic myeloid leukaemia who have maintained complete molecular remission for at least 2 years: the prospective, multicentre Stop Imatinib (STIM) trial. Lancet Oncol 2010;11(11):1029-35.

3. Takahashi N, Tauchi T, Kitamura K, Miyamura K, Saburi Y, Hatta $\mathrm{Y}$, et al. Deeper molecular response is a predictive factor for treatment-free remission after imatinib discontinuation in patients with chronic phase chronic myeloid leukemia: the JALSG-STIM213 study. Int J Hematol. 2018;107(2):185-93.

4. Etienne G, Guilhot J, Rea D, Rigal-Huguet F, Nicolini F, Charbonnier A, et al. Long-term follow-up of the French Stop imatinib (STIM1) study in patients with chronic myeloid leukemia. J Clin Oncol. 2017;35(3):298-305.

5. Clark R. Tyrosine kinase inhibitor therapy discontinuation for patients with chronic myeloid leukaemia in clinical practice. Curr Hematol Malig Rep. 2019;14(6):507-14.

Publisher's Note Springer Nature remains neutral with regard to jurisdictional claims in published maps and institutional affiliations.

Hiroki Yamaguchi

y-hiroki@fd6.so-net.ne.jp

1 Department of Hematology, Nippon Medical School, 1-1-5 Sendagi, Bunkyo-Ku, Tokyo 113-8603, Japan 